\title{
DNA amplification fingerprinting: Another diagnostic tool?
}

KR Rozee, WM Johnson

$U_{a}^{s}$ SE OF THE POLYMERASE CHAIN REACTION (PCR), amplification of targeted nucleotide sequences as a means of identifying microorganisms for diagnostic and epidemiologic purposes $(1,2)$, has initiated a transformation in laboratory based approaches to infectious disease diagnosis and was the subject of an earlier LCDC report (3). The high sensitivity and specificity of properly targeted long chain primer pairs and the great variety of specimens amenable to PCR analysis, including nonculturable specimens such as paraffin embedded tissues, has generated numerous diagnostic applications (4).

Another genetic approach has recently been suggested by two groups $(5,6)$ in which PCR amplification of DNA polymorphisms was directed by single small primers only eight to 10 nucleotides in length. Following polyacrylamide gel electrophoresis (PAGE), these demonstrate an array of amplicons that yield a banding fingerprint that is characteristic for each combination of short primer and DNA source. This technique has been designated DNA amplification fingerprinting (DAF).

The PCR conditions under which DAF produces reliable, consistent PAGE 'fingerprints', as one would expect considering the short single primers, is quite different from long, dual primer amplification and must be developed carefully for consistent results (7). Particularly important are the specialized silver staining method (8) required for resolution of small, as opposed to large, amplicons, and the primer concentrations required for effective priming.
DAF using two small primers has been suggested as another variation which may produce unique fingerprints that are not just sums of the amplicon patterns of the two primers run separately. This has been called 'multiplex DAF' by Caetano-Anollés et al (7) who have used it effectively with Staphylococcus aureus.

There appears to be some particular advantages to DAF compared to the more traditional PCR approach. The use of long, dual primer PCR requires that there be extensive preexisting knowledge of the target sequences. There is not such a requirement for DAF.

The conditions required for effective long chain, dual primer PCR are considerably more stringent with respect to hybridization and enzymatic conditions than for DAF. Multiple priming sites on each DNA strand are amplified efficiently by short primers under relaxed conditions and the number of amplicons reproducibly obtained in DAF is largely dependent on the short primer sequence rather than length, provided the number exceeds four (5-7).

The ability to tailor the number of amplicons in the product of PCR by the use of multiplex design and variation of the $\mathrm{G}+\mathrm{C}$ content of the short primers allows the laboratory to construct identification protocols for either rough grouping or fine typing, as required.

LCDC has begun the analysis of certain pseudomonads using this technology and we will shortly be reporting on its efficacy in our hands. Until then it would seem reasonable to predict 
that DAF technology will provide high versatility while retaining the selectivity and sensitivity of long, dual primer PCR and will shortly be part of the diagnostic trade of clinical microbiologists.

\section{REFERENCES}

1. Landegren U, Kaiser R, Caskey CT, Hood L. DNA diagnostics - Molecular techniques and automation. Science 1988;242:229-37.

2. Eisenstein BI. The polymerase chain reaction. A new method of using molecular genetics for medical diagnosis. N Engl J Med 1990;322:178-83.

3. Johnson WM, Rozee KR, Tyler SD. The polymerase chain reaction: An overview and development of diagnostic protocols at the LCDC. Can J Infect Dis 1991;2:89-91.
4. Reiss J, Cooper DN. Application of the polymerase chain reaction to the diagnosis of human genetic disease. Hum Genet 1990;85:1-8.

5. Williams JGK, Kubelik AR, Livak KJ, Rofolski SA, Tingley SV. DNA polymorphism amplified by arbitrary primers are useful as genetic markers. Nucleic Acids Res 1990;18:6531-5.

6. Welsh J, McClelland M. Fingerprinting genomes using PCR with arbitrary primers. Nucleic Acids Res 1990;18:7213-8.

7. Caetano-Anollés G, Bassam BJ, Gresshoff PM. DNA amplification fingerprinting using very short arbitrary oligonucleotide primers. Bio/Technology 1991;9:553-7.

8. Bassam BJ, Caetano-Anollés G, Gresshoff PM. Fast and sensitive silver staining of DNA in polyacrylamide gels. Anal Biochem 1991;196:80-3. 


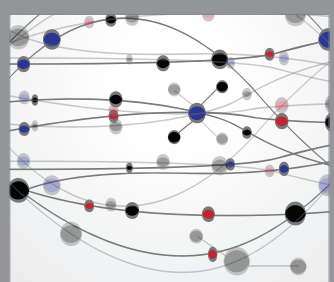

The Scientific World Journal
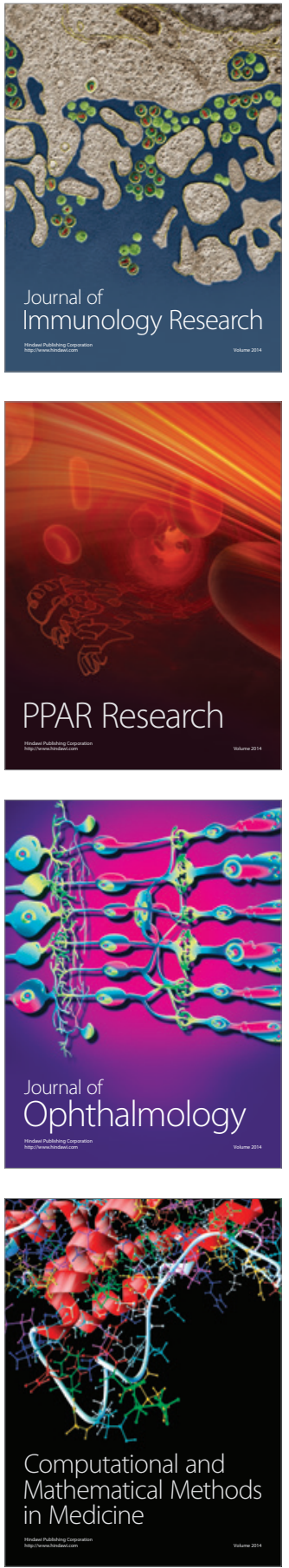

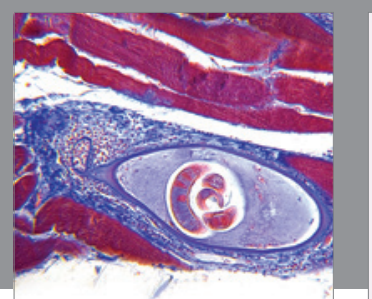

Gastroenterology Research and Practice

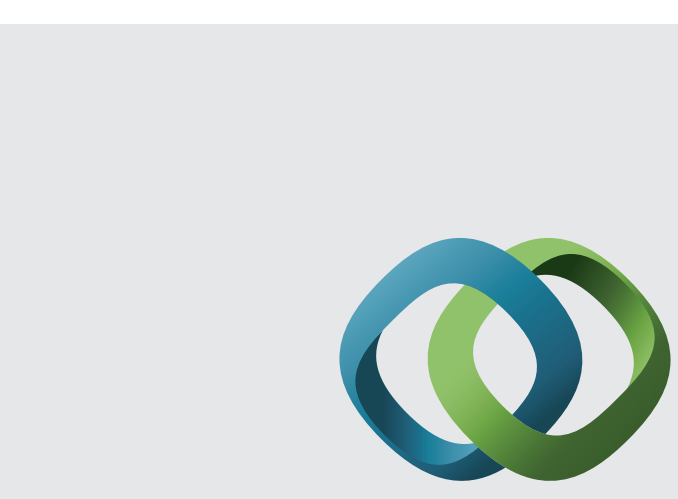

\section{Hindawi}

Submit your manuscripts at

http://www.hindawi.com
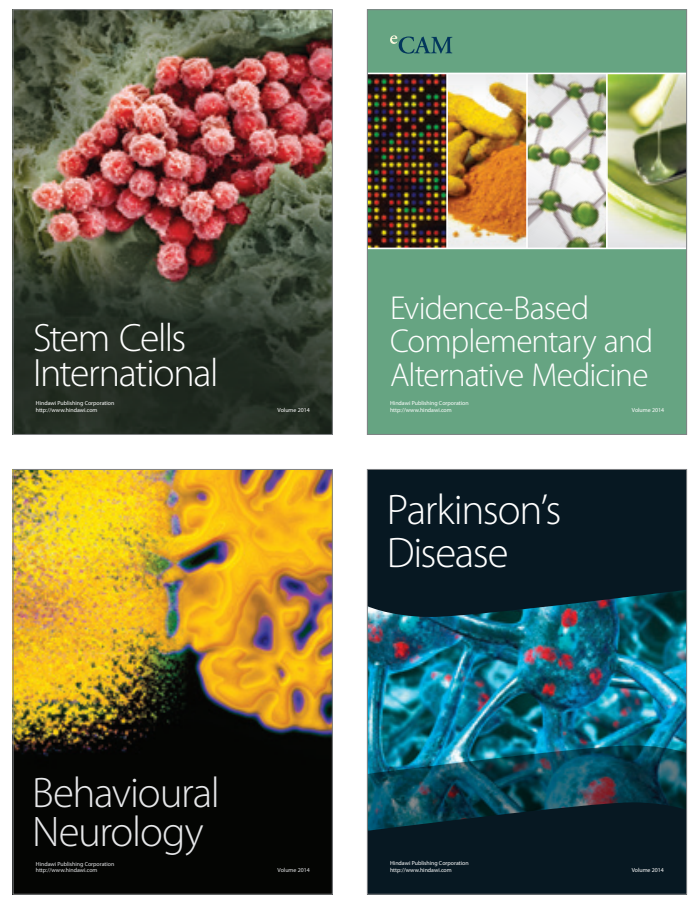
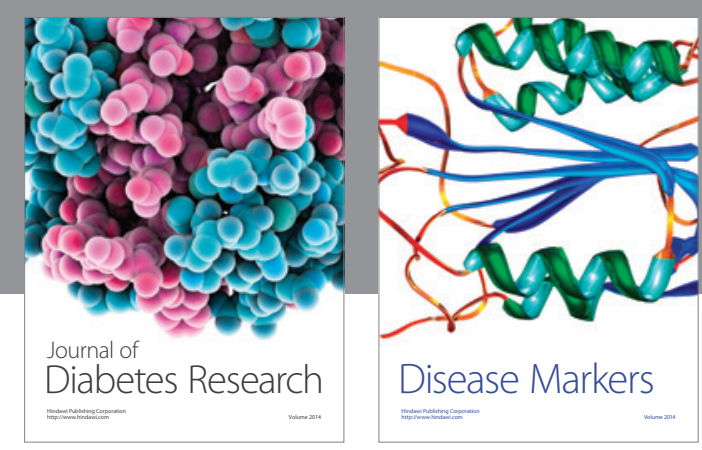

Disease Markers
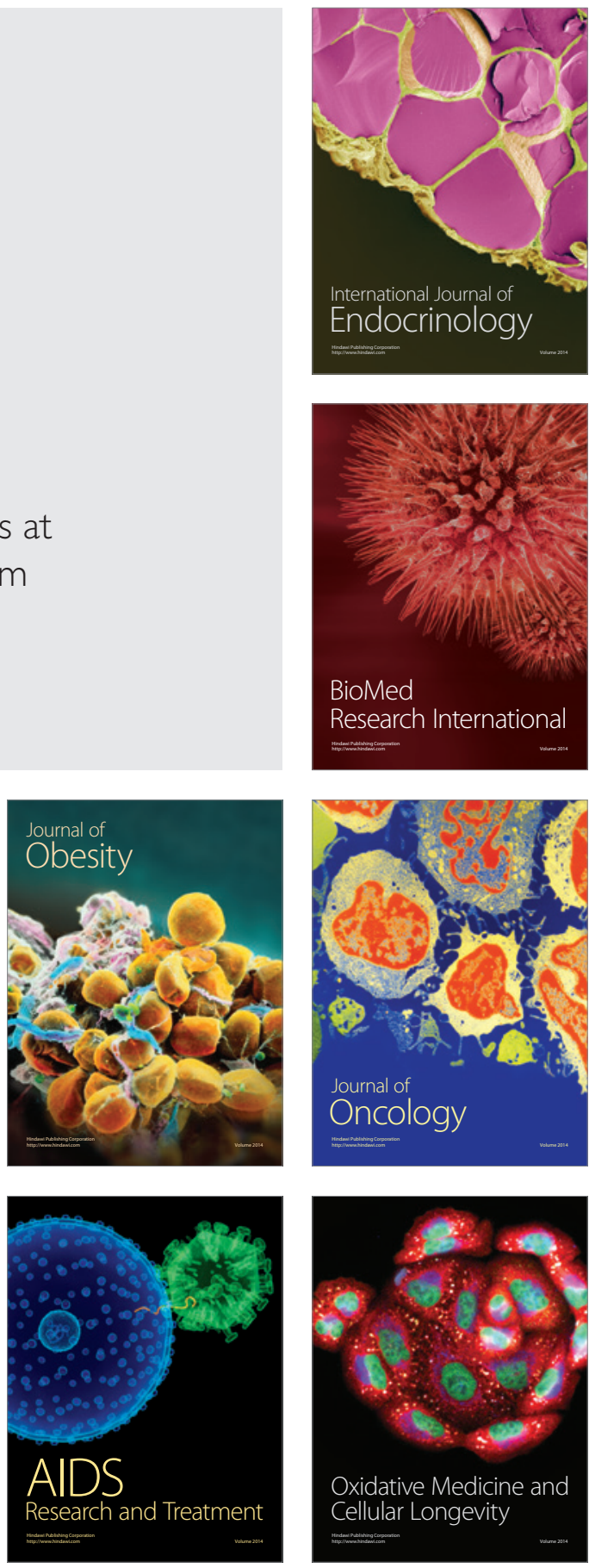